\title{
Mechanical and Durability Performance of Polyacrylonitrile Fiber Reinforced Concrete
}

\author{
Sheng-jun Fan * \\ ${ }^{a}$ School of Civil Engineering, Xi'an University of Architecture and Technology, Xi'an 710000, China
}

Received: August 12, 2015; Revised: October 5, 2015

\begin{abstract}
In this paper, the impact toughness, autogenous shrinkage, chloride penetration resistance, permeability resistance and abrasion resistance performance of prepared concrete reinforced with Polyacrylonitrile fiber (PAN fiber) were researched. The PAN fiber volume concentration percentages of cement were 0 , $0.5 \%, 1.0 \%, 1.5 \%$ and $2.0 \%$, respectively. The results showed that with the addition of PAN fiber, the toughness and durability performance were improved. Compared to the reference sample, the impact energy was significantly improved. The absorbed energy prevent specimens from deterioration by the mechanisms of matrix cracking, PAN fiber/matrix interface debonding, fiber pull-out and fiber rupture. Meanwhile, the autogenous shrinkage, chloride penetration resistance, permeability resistance and abrasion resistance performance were improved. Mercury intrusion porosimetry (MIP) technique found that concrete with PAN fiber has a better pore characterization. Among these specimens, the maximum improvement was obtained with 1.0 vol. $\%$ PAN fiber.
\end{abstract}

Keywords: concrete, polyacrylonitrile fiber (PAN fiber), impact energy, toughness, autogenous shrinkage, chloride penetration resistance, permeability resistance, abrasion resistance

\section{Introduction}

As for its low cost and satisfactory engineering properties, concrete is widely applied in the infrastructure construction in the world ${ }^{1-3}$. However, concrete is typically characterized as quasi-brittle and low tensile strength. When the concrete is loaded, the initially and discontinuous microcracks are appeared in this matrix, which limits the development of concrete science. The added micro-fiber can overcome these weaknesses and control the crack propagation effectively, which finally improved the mechanical and durability performance of concrete.

PAN fiber, shortened for Polyacrylonitrile Fiber, was a kind of synthetic fiber which made by acylonitrile copolymer. Recently, experimental tests have shown PAN fiber to have an average strength of $40 \mathrm{cN} / \mathrm{dtex}$. Their high stiffness, tensile strength, chemical resistance, and electrical and thermal conductivity make them attractive for applying as reinforcement for specimens, including concrete materials. In the lastest decade, as a kind of green material for concrete, PAN fiber is considered as a promising candidate in a wide range of applications $s^{4-8}$. Xu et al. ${ }^{9}$ studied the performance of fiber reinforced asphalt concrete (AC) under environmental temperature and water effects and he found that the fibers have significantly improved AC's rutting resistance, fatigue life, and toughness. The flexural strength and ultimate flexural strain, and the split indirect tensile strength (SITS) at low temperature have also improved. Yao \& Feng ${ }^{10}$ researched the durability of freezing/thawing resistance of polyacrylonitrile fiber reinforced concrete and the results indicated that the polyacrylonitrile fibers were of firm interface combined with concrete. The fibers have meshwork adjective function of resisting fatigue destruction. By adding suitable volume

*e-mail: fsj5759@126.com fraction of fibers, the durability of freezing/thawing resistance of concrete will be improved remarkably. Sun et al. ${ }^{11}$ put the short polyacrylonitrile-based carbon fibers (0.2 2.0 wt.\%) in concrete and tested the thermoelectric power (TEP) and conductivity. TEP in CFRC increases, with the content of short carbon fiber increasing from 0.2 to $1.0 \mathrm{wt} . \%$. As the content of carbon fiber reaches 1.2 wt.\%, TEP decreases abruptly. In the end, TEP is almost maintained marginally with increasing content of carbon fiber from 1.4 to $2.0 \mathrm{wt} . \%$.

In this paper, the impact toughness, autogenous shrinkage, chloride penetration resistance, permeability resistance and abrasion resistance performance of prepared concrete reinforced with PAN fiber were researched. The PAN fiber volume concentration percentages of cement were $0,0.5 \%$, $1.0 \%, 1.5 \%$ and $2.0 \%$ by cement, respectively. Finally, MIP was used to characterize the pore parameters of PAN fiber reinforced concrete specimens.

\section{Experimental}

\subsection{Materials}

The used materials for concrete were Ordinary Portland cement (42.5R), natural river sand (fineness modulus of 2.9) and natural coarse aggregate (maximum particle size of $25 \mathrm{~mm}, 5 \sim 15 \mathrm{~mm}$ is $30 \%$ and $15 \sim 25 \mathrm{~mm}$ is $70 \%$ ). Ordinary Portland cement (42.5R) was provided by Anhui Conch Cement Co., Ltd., and the correspondingly parameters were shown in Table 1. Natural river sand and natural coarse aggregate were both provided by Xi'an Jingtian Building Materials Co., Ltd. Polycarboxylate superplasticizer (PS), with water reduction efficiency of $30 \%$, was purchased from Xi'an Shenghua New Building Materials Co., Ltd. PAN fiber 
was supplied from Shandong Binzhou Qisu Materials Co., Ltd. and the physical parameters were shown in Table 2.

\subsection{Sample preparation}

The detailed mix proportion of prepared PAN fiber reinforced concrete was shown in Table 3. The water to cement ratio was 0.38 and the sand to aggregate ratio was $40 \%$, respectively. The preparation procedures involved: (1) cement, natural river sand and natural coarse aggregate were poured into the laboratory concrete mixer and for 2 minutes' mixing; (2) adding PAN fiber for another 1 minutes' mixing; (3) adding the weighed water (including $0.8 \% \mathrm{PS}$ ) in 30 seconds; (4) the final mixing was applied in 2 minute; (5) casting the prepared PAN fiber reinforced paste into the shaped molds and a electric vibrator was used to ensure good compaction. All specimens were demolded after 1 day and cured in a standard environment condition in moist room with a temperature of $20 \pm 1{ }^{\circ} \mathrm{C}$ and relative humidity of not less than $95 \%$.

\subsection{Testing procedures}

During the impact toughness test, a steel ball (4.5 kg), with no initial velocity, was dropped repeatly on the prepared PAN fiber reinforced concrete specimens of $457 \mathrm{~mm}$ height. The number of blows of first crack initiation and ultimate failure were recorded. The correspondingly equations were shown as follows:

$H=\frac{1}{2} g t^{2}$

$V=g t$

Impact energy during each drop,

$U=\frac{1}{2} m V^{2}$
The autogenous shrinkage of PAN fiber reinforced concrete specimens was performed by specimens $(100 \mathrm{~mm} \times 100 \mathrm{~mm} \times 400 \mathrm{~mm})$. The stainless steel gage studs were glued directly to the surface of the specimens maintaining a certain length. A length comparator was used to measure the distance during this procedure. From these measurements, the autogenous shrinkage was calculated.

Chloride penetration resistance performance of PAN fiber reinforced concrete specimens was performed on the cylindrical specimens with $50 \mathrm{~mm}$ height and $100 \mathrm{~mm}$ diameter. Firstly, the prepared PAN fiber reinforced concrete specimens were carried out for a saturation process for 24 hours, then fixed in the shaped molds. During this test, the $3.0 \%$ sodium chloride solution and $0.3 \mathrm{~mol} / \mathrm{L}$ sodium hydroxide solution were used. After 6 hours' circular telegram process, the electric flux of PAN fiber reinforced concrete specimens was recorded. Permeability resistance performance of PAN fiber reinforced concrete specimens were tested by using cylindrical specimens $(50 \mathrm{~mm}$ height and $100 \mathrm{~mm}$ diameter). One surface was exposed on water and they were weighed after 1, 5, 10, 20, and 30 minutes, 1 , $2,3,4,5$ and 6 hours, and $1,2,3,4,5,6,7,8$ and 9 days ${ }^{12}$. A concrete abrasion device was used in abrasion resistance test with a speed of $200 \mathrm{r} / \mathrm{min}$ and exerting load force of $100 \mathrm{~N}^{[13]}$. Three 2-minute abrasion periods were repeated on the surface of each PAN fiber reinforced concrete specimens and the abrasion weight loss was weighed. Each test was performed on three replicated specimens.

An automated mercury porosimeter (AUTOPORE IV 9500 series, Micromertics Instrument Corp., USA), with two low-pressure stations plus one high-pressure station and a maximum pressure of 33,000 psia for measurements, was used to measure the correspondingly porosity and the pore size distribution. During this procedure, PAN fiber reinforced concrete specimens were soaked in ethanol for about 1 day to stop the cement hydration reaction, and then dried in an oven at $60^{\circ} \mathrm{C}$.

Table 1. The detailed physical parameters of Ordinary Portland cement 42.5R.

\begin{tabular}{|c|c|c|c|c|c|c|c|}
\hline \multirow{2}{*}{$\begin{array}{c}\text { Specific } \\
\text { surface area } \\
\left(\mathrm{m}^{2} / \mathrm{kg}\right)\end{array}$} & \multirow{2}{*}{$\begin{array}{c}\text { Loss on } \\
\text { ignition (\%) }\end{array}$} & \multicolumn{2}{|c|}{$\begin{array}{l}\text { Setting time } \\
(\mathrm{min})\end{array}$} & \multicolumn{2}{|c|}{$\begin{array}{c}\text { Flexural strength } \\
\text { (MPa) }\end{array}$} & \multicolumn{2}{|c|}{$\begin{array}{c}\text { Compressive strength } \\
\text { (MPa) }\end{array}$} \\
\hline & & Initial setting & $\begin{array}{c}\text { Final } \\
\text { setting }\end{array}$ & 3d & $28 d$ & $3 d$ & $28 d$ \\
\hline 321 & 2.68 & 195 & 260 & 5.6 & 9.1 & 31.7 & 59.2 \\
\hline
\end{tabular}

Table 2. The detailed physical parameters of PAN fiber.

\begin{tabular}{cccccccc}
\hline PAN fiber & $\begin{array}{c}\text { Llength } \\
(\mathbf{m m})\end{array}$ & $\begin{array}{c}\text { Diameter } \\
(\boldsymbol{\mu m})\end{array}$ & $\begin{array}{c}\text { Tensile } \\
\text { strength } \\
(\mathbf{M P a})\end{array}$ & $\begin{array}{c}\text { Elastic } \\
\text { modulus } \\
(\mathbf{M P a})\end{array}$ & $\begin{array}{c}\text { Elongation } \\
\mathbf{( \% )}\end{array}$ & $\begin{array}{c}\text { Density } \\
\left(\mathbf{g} / \mathbf{c m}^{3}\right)\end{array}$ & $\begin{array}{c}\text { Electric } \\
\text { conductivity }\end{array}$ \\
\hline- & 10 & $20 \sim 40$ & $\geq 500$ & $\geq 3850$ & $10 \sim 28$ & 0.91 & High \\
\hline
\end{tabular}

Table 3. Mix proportion of the prepared PAN fiber reinforced concrete.

\begin{tabular}{|c|c|c|c|c|c|c|c|}
\hline No. & Water to cement ratio & $\begin{array}{c}\text { Cement } \\
\text { (kg) }\end{array}$ & $\begin{array}{c}\text { Coarse aggregate } \\
\text { (kg) }\end{array}$ & $\begin{array}{l}\text { River sand } \\
\quad \text { (kg) }\end{array}$ & $\begin{array}{l}\text { Water } \\
\text { (kg) }\end{array}$ & PS (\%) & $\begin{array}{l}\text { PAN fibers } \\
\text { (vol.\%) }\end{array}$ \\
\hline PAN-0 & 0.38 & 500 & 900 & 600 & 190 & 0.8 & 0 \\
\hline PAN-1 & 0.38 & 500 & 900 & 600 & 190 & 0.8 & 0.5 \\
\hline PAN-2 & 0.38 & 500 & 900 & 600 & 190 & 0.8 & 1.0 \\
\hline PAN-3 & 0.38 & 500 & 900 & 600 & 190 & 0.8 & 1.5 \\
\hline PAN-4 & 0.38 & 500 & 900 & 600 & 190 & 0.8 & 2.0 \\
\hline
\end{tabular}




\section{Results}

\subsection{Impact toughness performance}

A detailed impact toughness result was shown in Table 4. As for a elastic brittle material, the first crack initiation and ultimate failure of reference sample were occurred simultaneously. Compared to the reference sample, a significant improvement in the number of blows for first crack initiation and ultimate failure was obtained from the PAN fiber reinforced concrete specimens. The improving in impact energy at first crack initiation and failure varied from $66.7 \%$ to $116.7 \%$ and $166.7 \%$ to $250.0 \%$. The greatest impact toughness of the PAN fiber reinforced concrete specimens was gained by incorporating $1.0 \mathrm{vol} . \%$ PAN fibers, which obtained the maximum improvement of $250.0 \%$. The introduced PAN fibers absorbed impact energy to prevent specimens from deterioration by the mechanisms of matrix cracking, PAN fiber/matrix interface debonding, PAN fiber pull-out and PAN fiber rupture ${ }^{14,15}$. According to the lastest researches ${ }^{16,17}$, fiber reinforcement can be used to improve both the fatigue and toughness performance of concrete. When post-cracked strength or toughness is the concern, concrete containing more fibers and fibers with higher tensile strength are desirable. Conversely, too many fibers prevent adequate consolidation and aggregate interlock, which negatively influences performance.

\subsection{Autogenous shrinkage performance}

Prior works indicate that cement and concrete materials are sensitive to the microcrack formation at early ages, as a result of the volumetric changes due to the development of high autogenous shrinkage stresses ${ }^{18}$. By controlling and delaying the crack formation, the added PAN fibers can effectively solve the autogenous shrinkage problems of concrete. The detailed autogenous shrinkage results of PAN fiber reinforced concrete specimens were shown in Figure 1. Obviously, It could be found that the addition of PAN fibers limit the correspondingly autogenous shrinkage values. The shrinkage development is known to the proportional to the amount of the fine pores in the binder at early ages and a higher percentage of fine pores in matrix increase the risk of the development of autogenous shrinkage ${ }^{19,20}$. With the incorporation of PAN fibers, a magnificent $21.7 \%, 39.1 \%$, $26.1 \%$ and $17.4 \%$ reduction of the autogenous shrinkage was obtained. The addition of PAN fibers improved the pore parameters and concentrated the matrix, which finally resulted a lower shrinkage strain.

\subsection{Chloride penetration resistance performance}

The detailed chloride penetration resistance performance of PAN fiber reinforced concrete specimens was shown in Figure 2. The electric flux of reference sample was about
2540 C. However, the correspondingly electric flux was decreased by addition of PAN fibers in concrete matrix. With the increasing volume concentration percentages of PAN fibers, the electric flux of PAN fiber reinforced concrete was decreased and reached to a minimum value for 1.0 vol. $\%$ PAN fibers reinforced concrete sample, then started to increase. The added PAN fiber improved the pore parameters and concentrated the matrix, which finally improved the chloride penetration resistance performance of PAN fiber reinforced concrete specimens ${ }^{21,22}$. Moreover, Tuan et al. ${ }^{23}$ found the results of electrical resistivity, chloride ion penetration and ultrasonic pulse velocity tests confirmed that HSFR-SCC had

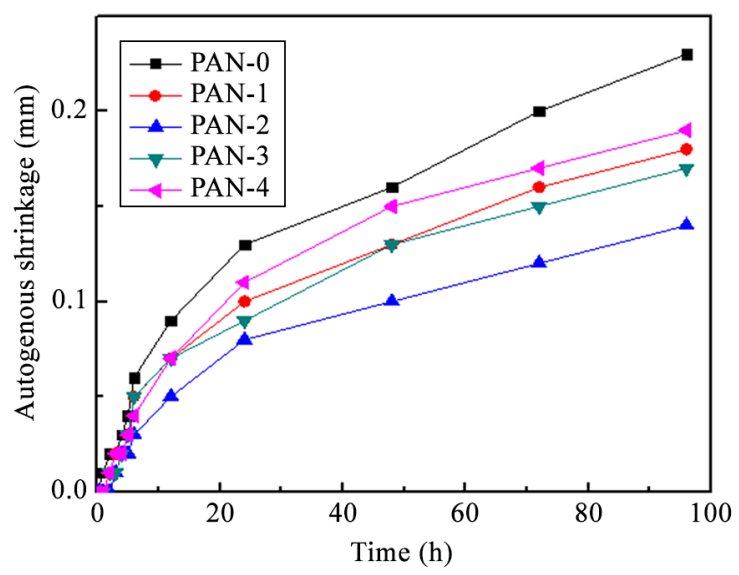

Figure 1. Autogenous shrinkage performance of PAN fiber reinforced concrete.

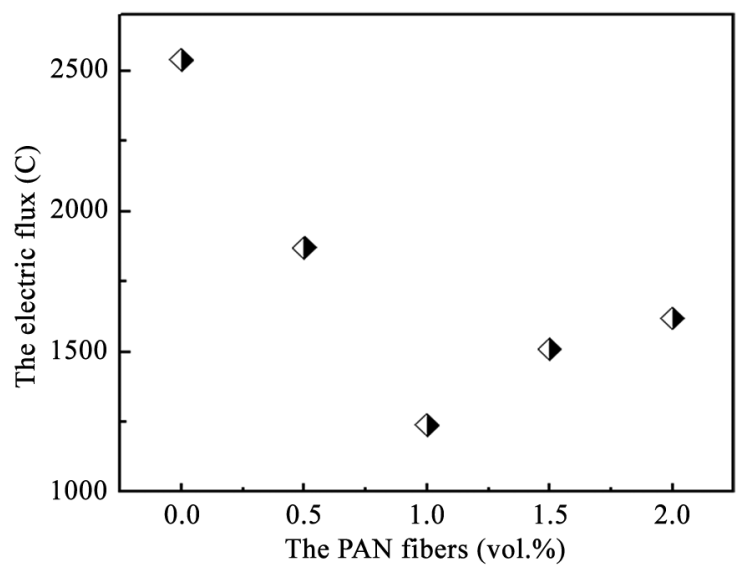

Figure 2. Chloride penetration resistance performance of PAN fiber reinforced concrete.

Table 4. Impact toughness performance of PAN fiber reinforced concrete.

\begin{tabular}{cccccc}
\hline \multirow{2}{*}{ No. } & \multirow{2}{*}{$\begin{array}{c}\text { PAN fibers } \\
(\text { vol. } \%)\end{array}$} & First crack & Failure & First crack & Failure \\
\cline { 3 - 6 } & 0 & 6 & 6 & 121.2 & 121.2 \\
PAN-0 & 0.5 & 10 & 16 & 202.0 & 323.2 \\
PAN-1 & 1.0 & 13 & 21 & 262.6 & 424.2 \\
PAN-2 & 1.5 & 13 & 17 & 262.6 & 343.4 \\
PAN-3 & 2.0 & 12 & 17 & 242.4 & 343.4 \\
PAN-4 & & & & & \\
\hline
\end{tabular}


enough endurance against deterioration, lower chloride ion penetrability and minimum reinforcement corrosion rate.

\subsection{Permeability resistance performance}

The detailed permeability resistance performance, i.e. permeability depth, was recorded in Figure 3. Compared to the reference sample, the PAN fiber reinforced concrete specimens have a lower permeability depth, which showed a relatively lower permeability rate. The pore parameters were improved and the specimens matrix became compacted after introduction of PAN fibers into the matrix. Finally, the correspondingly permeability resistance performance were enhanced. Compared to the permeability depth of reference specimen $(2.67 \mathrm{~mm})$, the permeability depth of PAN fiber reinforced concrete specimens were lower by $12.7 \%, 27.7 \%$, $19.8 \%$ and $9.0 \%$, respectively.

\subsection{Abrasion resistance performance}

The detailed abrasion weight loss was recorded in Table 5. With the increasing volume concentration percentages of PAN fibers, the abrasion weight loss decreased to the minimum value, and then started to grow. This trend was similar with the result of the tests above. The calculated abrasion weight loss of each PAN fiber reinforced concrete was 18.0, 16.3, $12.9,14.7$ and $15.9 \mathrm{~g}$, respectively ${ }^{24}$. Compared to reference specimen, the abrasion weight loss of PAN fiber reinforced concrete specimens were lower by $9.4 \%, 28.3 \%, 18.3 \%$ and $11.7 \%$, respectively.

\subsection{Pore parameter analysis}

MIP technique was widely used to analyze the pore parameters in concrete science, e.g., porosity, average pore diameter and pore diameter ${ }^{25,26}$. The detailed of pore characterizations summarized in Table 6. Figure 4 shows the variation of $\log$ differential intrusion $(\mathrm{mL} / \mathrm{g})$ with pore size diameter $(\mathrm{nm})$, and the points of inflection represent where clusters of pores of a particular diameter occur. It can

Table 5. Abrasion resistance performance of PAN fiber reinforced concrete.

\begin{tabular}{cccccc}
\hline & \multirow{2}{*}{$\begin{array}{c}\text { PAN } \\
\text { fiber }\end{array}$} & \multicolumn{3}{c}{ Abrasion weight loss (g) } & \\
\cline { 3 - 5 } & (vol.\%) & $\begin{array}{c}\text { First } \\
\text { time }\end{array}$ & $\begin{array}{c}\text { Second } \\
\text { time }\end{array}$ & $\begin{array}{c}\text { Third } \\
\text { time }\end{array}$ & $\begin{array}{c}\text { (g) } \\
\text { (g) }\end{array}$ \\
\hline PAN-0 & 0 & 17.8 & 18.3 & 17.9 & 18.0 \\
PAN-1 & 0.5 & 16.3 & 15.9 & 16.7 & 16.3 \\
PAN-2 & 1.0 & 12.1 & 13.6 & 12.9 & 12.9 \\
PAN-3 & 1.5 & 14.2 & 15.1 & 14.8 & 14.7 \\
PAN-4 & 2.0 & 15.3 & 16.3 & 16.0 & 15.9 \\
\hline
\end{tabular}

be obviously observed that the added PAN fiber effectively improve the pore parameter of PAN fiber reinforced concrete specimens, the porosity was decreased and the pore diameter was concentrated. This improving trend is similar with that of toughness and durability performance results. The porosity of reference concrete specimen is about $23.1 \%$, while the porosity values of PAN fiber reinforced concrete specimens are much lower, about $17.2 \%, 13.4 \%, 16.6 \%$ and $19.5 \%$, respectively.

With the added PAN fiber in concrete matrix, the pore size was concentrated, which was reflected in average pore diameter area. Compared to reference specimen, the average pore diameter of PAN fiber reinforced concrete specimens were lower by $18.7 \%, 58.0 \%, 36.3 \%$ and $18.4 \%$, respectively.

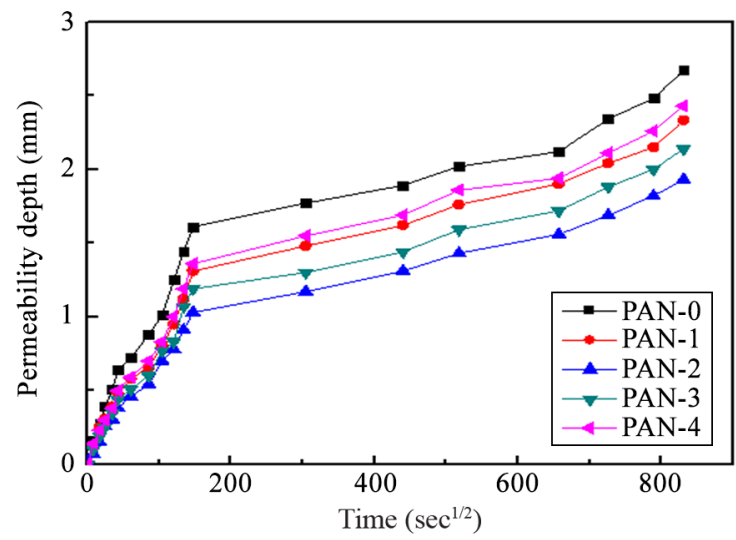

Figure 3. Permeability resistance performance of PAN fiber reinforced concrete.

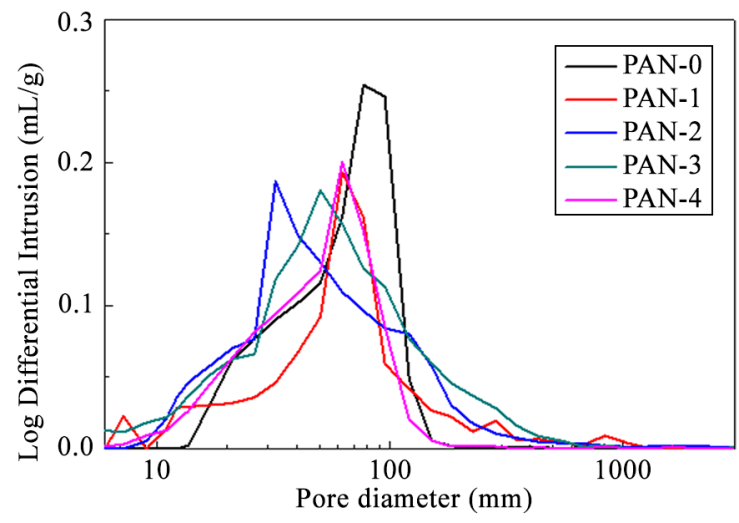

Figure 4. MIP analysis of pore parameters of PAN fiber reinforced concrete.

Table 6. Pore parameter of PAN fiber reinforced concrete.

\begin{tabular}{|c|c|c|c|c|c|c|c|}
\hline Sample & $\begin{array}{c}\text { Total } \\
\text { intrusion } \\
\text { volume/ } \\
\text { (mL/g) }\end{array}$ & $\begin{array}{c}\text { Total pore } \\
\text { area/ }\left(\mathrm{m}^{2} / \mathrm{g}\right)\end{array}$ & $\begin{array}{c}\text { Median pore } \\
\text { diameter } \\
\text { (volume)/ nm }\end{array}$ & $\begin{array}{c}\text { Median pore } \\
\text { diameter } \\
\text { (area)/ nm }\end{array}$ & $\begin{array}{l}\text { Average pore } \\
\text { diameter/ nm }\end{array}$ & $\begin{array}{c}\text { Apparent } \\
\text { (skeletal) } \\
\text { density/ (g/ } \\
\text { mL) }\end{array}$ & $\begin{array}{c}\text { Porosity/ } \\
\%\end{array}$ \\
\hline PAN-0 & 0.1277 & 9.134 & 83.1 & 47.0 & 77.1 & 2.53 & 23.1 \\
\hline PAN-1 & 0.1063 & 11.548 & 58.6 & 28.6 & 62.7 & 2.67 & 17.2 \\
\hline PAN-2 & 0.0845 & 14.437 & 47.2 & 18.3 & 32.4 & 2.91 & 13.4 \\
\hline PAN-3 & 0.1024 & 11.158 & 51.0 & 23.4 & 49.1 & 2.78 & 16.6 \\
\hline PAN-4 & 0.1183 & 11.981 & 68.9 & 35.5 & 62.9 & 2.52 & 19.5 \\
\hline
\end{tabular}


As a kind of porous material, concrete material possesses a worse frost resistance performance for its weaker pore characterization. The added PAN fiber with a certain content improve the pore parameters of these PAN fiber reinforced concrete specimens. Ultimately, the toughness and durability performance of these specimens are improved, including autogenous shrinkage, chloride penetration resistance, permeability resistance and abrasion resistance performance.

\section{Conclusions}

In this paper, the impact toughness, autogenous shrinkage, chloride penetration resistance, permeability resistance and abrasion resistance performance of prepared PAN fiber reinforced concrete were researched. The PAN fiber volume concentration percentages of cement in concrete matrix were $0,0.5 \%, 1.0 \%, 1.5 \%$ and $2.0 \%$, respectively. Compared to the reference sample, the added PAN fiber improved the toughness of concrete. During the crack propagation process, the absorbed fracture energy was provided by the mechanisms of matrix cracking, PAN fiber/matrix interface debonding, fiber pull-out and fiber rupture. A significant improvement in the number of blows for first crack initiation and ultimate failure was obtained from the PAN fiber reinforced concrete specimens. The improving in impact energy at first crack initiation and failure varied from 66.7 to $116.7 \%$ and $166.7 \%$ to $250.0 \%$. The greatest impact toughness of the PAN fiber reinforced concrete specimens was gained by incorporating 1.0 vol.\% PAN fibers, which obtained the maximum improvement of $250.0 \%$.

\section{Reference}

1. Tyson BM, Abu Al-Rub RK, Yazdanbakhsh A and Grasley Z. Carbon nanotubes and carbon nanofibers for enhancing the mechanical properties of nanocomposite cementitious materials. Journal of Materials in Civil Engineering. 2011; 23(7):1028-1035. http://dx.doi.org/10.1061/(ASCE)MT.1943-5533.0000266.

2. Tabatabaei ZS, Volz JS, Baird J, Gliha BP and Keener DI. Experimental and numerical analyses of long carbon fiber reinforced concrete panels exposed to blast loading. International Journal of Impact Engineering. 2013; 57:70-80. http://dx.doi. org/10.1016/j.ijimpeng.2013.01.006.

3. Zhao X and He XJ. High-toughness and durability performance characterization of concrete reinforced with polyvinyl alcohol fibers. Materials Express. 2014; 4(3):247-252. http://dx.doi. org/10.1166/mex.2014.1170.

4. Shunkevich AA, Akulich ZI, Mediak GV and Soldatov VS. Acid-base properties of ion exchangers. III. Anion exchangers on the basis of polyacrylonitrile fiber. Reactive \& Functional Polymers. 2005; 63(1):27-34. http://dx.doi.org/10.1016/j. reactfunctpolym.2005.02.002.

5. Zaini MAA, Amano Y and Machida M. Adsorption of heavy metals onto activated carbons derived from polyacrylonitrile fiber. Journal of Hazardous Materials. 2010; 180(1-3):552-560. http://dx.doi.org/10.1016/j.jhazmat.2010.04.069. PMid:20462692.

6. Deng S, Bai R and Chen JP. Behaviors and mechanisms of copper adsorption on hydrolyzed polyacrylonitrile fibers. Journal of Colloid and Interface Science. 2003; 260(2):265-272. PMid:12686174.

7. Chae HG, Sreekumar TV, Uchida T and Kumar S. A comparison of reinforcement efficiency of various types of carbon nanotubes
Obviously, the addition of PAN fibers improved the durability performance of concrete, including autogenous shrinkage, chloride penetration resistance, permeability resistance and abrasion resistance performance. With the incorporation of PAN fibers, a magnificent $21.7 \%, 39.1 \%$, $26.1 \%$ and $17.4 \%$ reduction of the autogenous shrinkage was obtained. Also, the electric flux and abrasion weight loss of PAN fiber reinforced concrete was decreased and reached to a minimum value for 1.0 vol. $\%$ PAN fibers reinforced concrete sample, then started to increase. Compared to the reference sample, the PAN fiber reinforced concrete specimens have a similar permeability depth at early time, and then the permeability depth was less than that of the reference sample after 2 days, which showed a relatively lower permeability rate. The addition of PAN fibers improved the pore parameters and concentrated the matrix, which finally improved the correspondingly performance.

Further research is necessary to obtain better characterizations and more performances need to be explored. The results of this research contribute to the knowledge of PAN fiber reinforced concrete.

\section{Acknowledgements}

The authors would like to express appreciation for the financial support by the National Youth Science Foundation of China (51408459) and the Science and Technology Foundation of Ministry of Housing and Urban-Rural Development of China (2014-R1-009).

in polyacrylonitrile fiber. Polymer. 2005; 46(24):10925-10935. http://dx.doi.org/10.1016/j.polymer.2005.08.092.

8. Rahaman MSA, Ismail AF and Mustafa A. A review of heat treatment on polyacrylonitrile fiber. Polymer Degradation \& Stability. 2007; 92(8):1421-1432. http://dx.doi.org/10.1016/j. polymdegradstab.2007.03.023.

9. $\mathrm{Xu} \mathrm{Q}, \mathrm{Chen} \mathrm{H}$ and Prozzi JA. Performance of fiber reinforced asphalt concrete under environmental temperature and water effects. Construction \& Building Materials. 2010; 24(10):2003-2010. http://dx.doi.org/10.1016/j.conbuildmat.2010.03.012.

10. Yao W and Feng W. Study on durability of freezing/thawing resistance of polyacrylonitrile fiber reinforced concrete. Industrial Construction. 2003; 33(11):43-45.

11. Sun M, Li Z, Mao Q and Shen D. Thermoelectric percolation phenomena in carbon fiber-reinforced concrete. Cement and Concrete Research. 1998; 28(12):1707-1712. http://dx.doi. org/10.1016/S0008-8846(98)00161-6.

12. Rapoport J, Aldea C-M, Shah SP, Ankenman B and Karr A. Permeability of cracked steel fiber-reinforced concrete. Journal of Materials in Civil Engineering. 2002; 14(4):355-358. http:// dx.doi.org/10.1061/(ASCE)0899-1561(2002)14:4(355).

13. Horszczaruk E. Abrasion resistance of high-strength concrete in hydraulic structures. Wear. 2005; 259(1-6):62-69. http:// dx.doi.org/10.1016/j.wear.2005.02.079.

14. Toutanji H, McNeil S and Bayasi Z. Chloride permeability and impact resistance of polypropylene-fiber-reinforced silica fume concrete. Cement and Concrete Research. 1998; 28(7):961-968. http://dx.doi.org/10.1016/S0008-8846(98)00073-8.

15. Banthia N, Yan C and Sakai K. Impact resistance of fiber reinforced concrete at subnormal temperature. Cement and 
Concrete Composites. 1998; 20(5):393-404. http://dx.doi. org/10.1016/S0958-9465(98)00015-8.

16. Mulheron M. Evaluation of the fatigue and toughness of fiber reinforced concrete for use as a new highway pavement design. [Thesis]. Kansas: University of Missouri; 2015. 108 p.

17. Cao P, Feng D, Zhou C and Zuo W. Study on fracture behavior of polypropylene fiber reinforced concrete with bending beam test and digital speckle method. Computers and Concrete. 2014; 14(5):527-546. http://dx.doi.org/10.12989/cac.2014.14.5.527.

18. Radlinska A, Rajabipour F, Bucher B, Henkensiefken R, Sant $\mathrm{G}$ and Weiss J. Shrinkage mitigation strategies in cement systems: a closer look at differences in sealed and unsealed behavior. Transportation Research Record: Journal of the Transportation Research Board. 2008; 2070:59-67. http:// dx.doi.org/10.3141/2070-08.

19. Lee KM, Lee HK, Lee SH and Kim GY. Autogenous shrinkage of concrete containing granulated blast-furnace slag. Cement and Concrete Research. 2006; 36(7):1279-1285. http://dx.doi. org/10.1016/j.cemconres.2006.01.005.

20. Craeye B, Schutter GD, Desmet B, Vantomme J, Heirman G, Vandewalle L, et al. Effect of mineral filler type on autogenous shrinkage of self-compacting concrete. Cement and Concrete Research. 2010; 40(6):908-913. http://dx.doi.org/10.1016/j. cemconres.2010.01.014.

21. Ramezanianpour AA, Pilvar A, Mahdikhani M and Moodi F. Practical evaluation of relationship between concrete resistivity, water penetration, rapid chloride penetration and compressive strength. Construction \& Building Materials. 2011;25(5):2472-2479. http://dx.doi.org/10.1016/j.conbuildmat.2010.11.069.

22. Andrade C, Prieto M, Tanner P, Tavares F and d'Andrea R. Testing and modelling chloride penetration into concrete. Construction \& Building Materials. 2013; 39:9-18. http:// dx.doi.org/10.1016/j.conbuildmat.2012.08.012.

23. Tuan BLA, Tesfamariam MG, Hwang C-L, Chen C-T, Chen $\mathrm{Y}-\mathrm{Y}$ and Lin K-L. Effect of fiber type and content on properties of high-strength fiber reinforced self-consolidating concrete. Computers and Concrete. 2014; 14(3):299-313.

24. Grdic ZJ, Curcic GAT, Ristic NS and Despotovic IM. Abrasion resistance of concrete micro-reinforced with polypropylene fibers. Construction \& Building Materials. 2012; 27(1):305-312. http://dx.doi.org/10.1016/j.conbuildmat.2011.07.044.

25. Kondraivendhan B, Divsholi BS and Teng S. Estimation of strength, permeability and hydraulic diffusivity of pozzolana blendd concrete through pore size distribution. Journal of Advanced Concrete Technology. 2013; 11(9):230-237. http:// dx.doi.org/10.3151/jact.11.230.

26. Kaufmann J, Loser R and Leemann A. Analysis of cementbonded materials by multi-cycle mercury intrusion and nitrogen sorption. Journal of Colloid and Interface Science. 2009; 336(2):730-737. http://dx.doi.org/10.1016/j.jcis.2009.05.029. PMid:19505695. 